\title{
Effect of non-sucrose sweet tasting solution on neonatal heel prick responses
}

\author{
Luca A Ramenghi, Gillian C Griffith, Christopher M Wood, Malcolm I Levene
}

\begin{abstract}
A substance commercially described as 'sugar free,' used as a sweetener for paracetamol suspension, was evaluated on measures of neonatal pain. Sixty infants were randomly allocated to receive one of four solutions before heel stab blood sampling: sterile water (placebo); 25 or $50 \%$ sucrose (weight/volume); and the commercial sweet-tasting solution. There was a significant reduction in crying time and pain score 3 minutes after the painful stimulus in all groups compared with the controls.
\end{abstract}

It is concluded that this sweet-tasting solution has analgesic effects as potent as those of concentrated sucrose solutions. (Arch Dis Child 1996; 74: F129-F131) behavioural response, heel prick.

All healthy newborn infants born in Britain are exposed to iatrogenic painful procedures. We estimate that $15 \%$ of term babies undergo an additional two to five heel prick sampling procedures in the first week of life. ${ }^{1}$ These painful procedures may be considered minor, but recent research has suggested that babies' early pain experience may affect adversely their pain response in later infancy. ${ }^{2}$

We have recently reported that concentrated sucrose solution significantly reduces the duration of cry in newborn babies when given immediately before a heel prick blood sampling for serum bilirubin and this may be mediated by release of endogenous opiates. ${ }^{1-3}$ The use of concentrated sucrose may be criticised in light of its high tonicity and its cariogenic effect on erupted teeth. We therefore investigated a sweet-tasting solution commercially described as 'sugar free' and used as a vehicle for paracetamol (Calpol) for its effect on reducing pain response following heel prick blood sampling.

Division of Paediatrics and Child Health University of Leeds School of Medicine, D Floor, Clarendon Wing, The General Infirmary at Leeds, Leeds LS2 9NS L A Ramenghi

G C Griffith

C $M$ Wood

M I Levene

Correspondence to: Professor Malcolm Levene. Accepted 30 October 1995

Healthy term newborn infants who required
Keywords: analgesia, sweet-tasting solution, sucrose,

heel prick blood sampling for serum bilirubin estimations were recruited. Criteria for inclusion were: bithweight above $2500 \mathrm{~g}$; gestation 37-42 weeks; Apgar score of 7-10 at 5 minutes and no previous exposure to naloxone.

Infants were fully clothed apart from the foot which was used for sampling. Before skin preparation a pulse oximeter was applied to the baby's hand or contralateral foot to monitor heart rate throughout the study period. Test solution $(2 \mathrm{ml})$ was syringed into the baby's mouth for 1 minute. The solution was applied mainly to the anterior part of the tongue to best promote taste perception. ${ }^{4-5}$ Two minutes after beginning to administer the solution the heel prick was performed by lancing and gently squeezing the heel which had been cleaned with a sterile swab. Because the method of performing blood samples may affect the nociceptive response, all heel pricks were inflicted by one experienced nurse standardising the procedure and recording the time spent squeezing. Changes in four facial expressions (brow bulge, eye squeeze, nasolabial furrow and open mouth) and the presence of crying related to the heel prick were recorded by the same observer at $-2,-1,0,1,2,3$, and 5 minutes on a $0-5$ scale, giving a score of 1 if present and 0 if absent to each item for each criterion. The baby's behavioural state was scored before heel lancing. ${ }^{15-8}$ Crying during sampling and in the 3 minutes after heel prick were recorded on to a tape recorder. The first cry was defined as the duration of audible distressed vocalisations with a continuous pattern before a quiet interval of 5 seconds from the time of the painful stimulus.

Babies were allocated at random to receive one of four solutions: sterile water (control); 25 or $50 \%$ sucrose (weight/volume); and the sweet-tasting commercial Calpol solution without paracetamol (Burroughs Wellcome). This contains Lycasin (hydrogenated glucose syrup) as the sweetening agent in a $40 \% \mathrm{w} / \mathrm{v}$ solution. Fifteen babies were required in each group to achieve the $80 \%$ power necessary to show a $50 \%$ reduction in crying time $(P=0.05)$.

Table 1 Details of neonates studied and changes in pain score in response to heel lance

\begin{tabular}{|c|c|c|c|c|c|c|c|c|c|}
\hline Solution & No & $\begin{array}{l}\text { Median } \\
\text { gestational } \\
\text { age } \\
\text { (weeks) } \\
\text { (range) }\end{array}$ & $\begin{array}{l}\text { Median } \\
\text { postnatal } \\
\text { age } \\
\text { (days) } \\
\text { (range) }\end{array}$ & $\begin{array}{l}\text { Median } \\
\text { arousal } \\
\text { state score } \\
(0-5) \\
\text { (range) }\end{array}$ & $\begin{array}{l}\text { Median } \\
\text { time from } \\
\text { last feed } \\
\text { (minutes) } \\
\text { (range) }\end{array}$ & $\begin{array}{l}\text { Median time } \\
\text { spent squeezing } \\
\text { heel } \\
\text { (seconds) } \\
\text { (range) }\end{array}$ & $\begin{array}{l}\text { Pain score } 1 \\
\text { minute before } \\
\text { heel prick } \\
(t=-1) \\
\text { (range) }\end{array}$ & $\begin{array}{l}\text { Pain score } \\
\text { at time of } \\
\text { heel prick } \\
(t=0) \\
\text { (range) }\end{array}$ & $\begin{array}{l}\text { Pain score } \\
3 \text { minutes } \\
\text { after heel } \\
\text { prick }(t=3) \\
\text { (range) }\end{array}$ \\
\hline $\begin{array}{l}50 \% \text { Scrose } \\
\text { Water (control) } \\
25 \% \text { Sucrose } \\
\text { Calpol solution }\end{array}$ & $\begin{array}{l}15 \\
15 \\
15 \\
15\end{array}$ & $\begin{array}{l}39(38-40) \\
38(37-40) \\
39(38-40) \\
39(39-40)\end{array}$ & $\begin{array}{l}3(2-4) \\
3(2-4) \\
4(3-5) \\
3(2-3)\end{array}$ & $\begin{array}{l}2(1-3) \\
1(1-3) \\
1(1-3) \\
2(0-3)\end{array}$ & $\begin{array}{l}45(30-80) \\
90(20-150) \\
90(70-198) \\
60(45-120)\end{array}$ & $\begin{array}{l}80(70-115) \\
90(50-148) \\
85(60-98) \\
90(68-108)\end{array}$ & $\begin{array}{l}0(0-0) \\
2(1-3) \\
0(0-0) \\
0(0-0)\end{array}$ & $\begin{array}{l}3(3-5) \\
4(3-5) \\
4(3-5) \\
4(3-5)\end{array}$ & $\begin{array}{l}0(0-3) \\
2(1-5) \\
0(0-2) \\
0(0-1)\end{array}$ \\
\hline
\end{tabular}




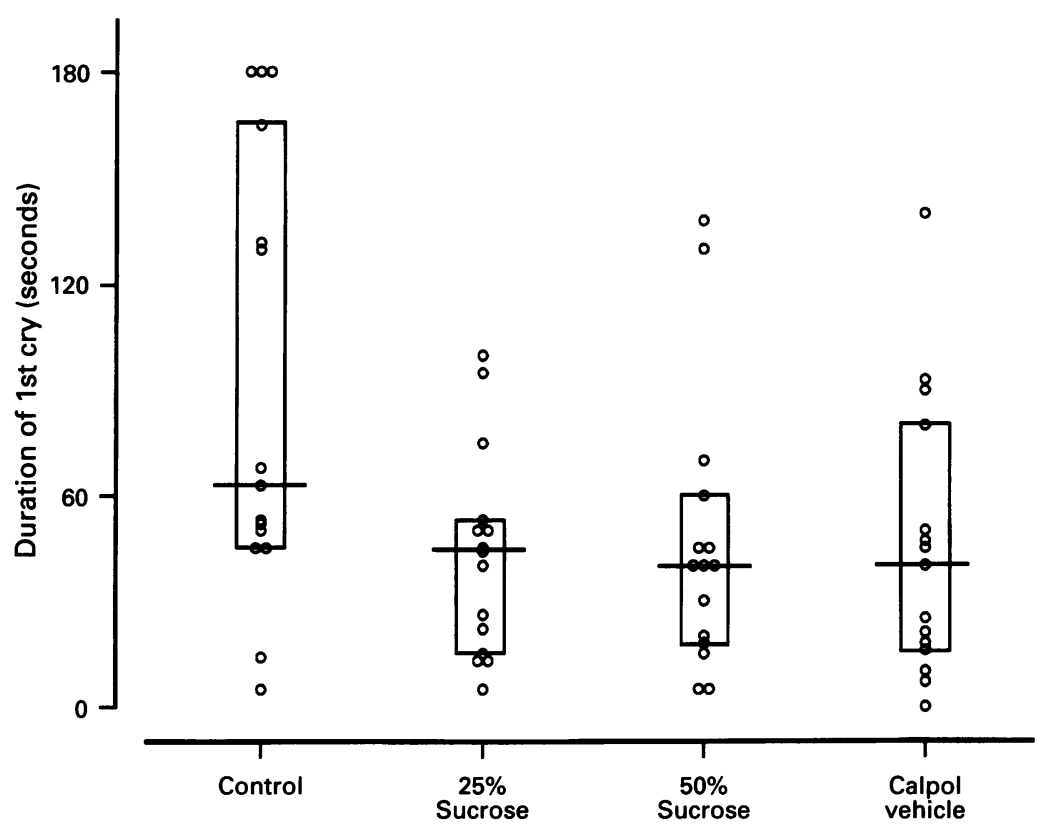

Figure 1 Duration of first crying after heel prick in 60 babies given sterile water (controls), $25 \%$ or $50 \%$ sucrose, and non-sucrose sweet-tasting Calpol solution. Points are individual values. Horizontal lines and boxes represent median values and interquartile ranges.

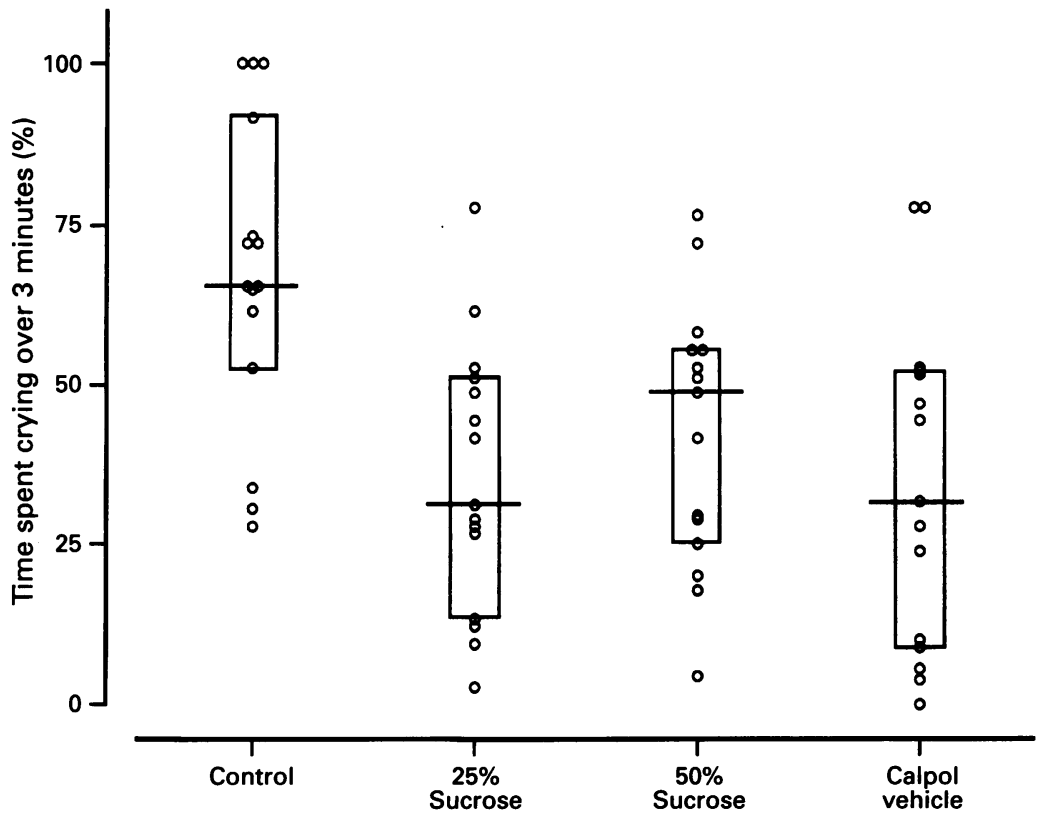

Figure 2 Percentage time spent crying in the first 3 minutes after heel prick in the 60 babies grouped as in fig 1. and time spent squeezing the heel (table 1). Changes in the babies' pain scores in each group are shown in table 1 . The median crying time and the median duration of first cry are illustrated in fig 1 . Figure 2 shows the duration of crying in the first 3 minutes after heel prick in each treatment group. Heart rate changes are illustrated in fig 3.

There was a significant reduction in both the duration of first cry and the percentage crying time during the first 3 minutes in all groups (25 and $50 \%$ sucrose; Calpol vehicle solution) compared with controls $(P=0.02)$.

The pain score was significantly higher in the placebo group compared with the other groups 3 minutes after $(P=0.05)$ and 1 minute before lancing $(P=0 \cdot 04)$.

There was a significant increase in heart rate between 3 minutes after the painful procedure in the control group compared with the $50 \%$ sucrose and Calpol vehicle solution group $(P=0.009)$.

\section{Discussion}

Cry is still considered the most sensitive behavioural response to a noxious stimulus in neonates. ${ }^{9}$ We found that neonates who had been given oral placebo (sterile water) before heel pricks had significantly longer crying time than babies given a small volume of concentrated sucrose and a sweet-tasting, non-sucrose solution. The significant reduction in heart rate and pain score 3 minutes after heel prick in the babies receiving the Calpol vehicle solution as well as concentrated sucrose solution tends to confirm the analgesic effects of these forms of treatment.

The major finding of this study is to extend to a non-sucrose sweet-tasting solution our recent observation concerning the apparent analgesic effects of concentrated sucrose solutions. ${ }^{1}$ We had subjectively observed that young infants given Calpol solution for perceived pain or fever rapidly settled within seconds of its administration. This action is too rapid to be attributable to the analgesic effects of the paracetamol. We were intrigued to discover whether the sweet, non-sucrose vehicle of Calpol solution may have independent effects on pain.

The sweet taste of Calpol solution is achieved by hydrogenated glucose. The manufacturers of Calpol describe their solution as 'sugar free' because it does not contain sucrose. The speed of analgesic response of the Calpol solution is consistent with a preabsorptive mechanism which stimulates endogenous opiate release, as has been proposed as an explanation for the analgesic effects of sucrose. ${ }^{3} 10-12$

The reduction in pain perception in the neonate may be achieved by a variety of effects with possibly cumulative action. Previous studies have shown that non-nutritive sucking on a pacifier attenuates behavioural distress during heel stick procedures. ${ }^{13}$

Newborns' behaviour may often be influenced by maternal contact. We have chosen to investigate the effect of a sweet solution in the 


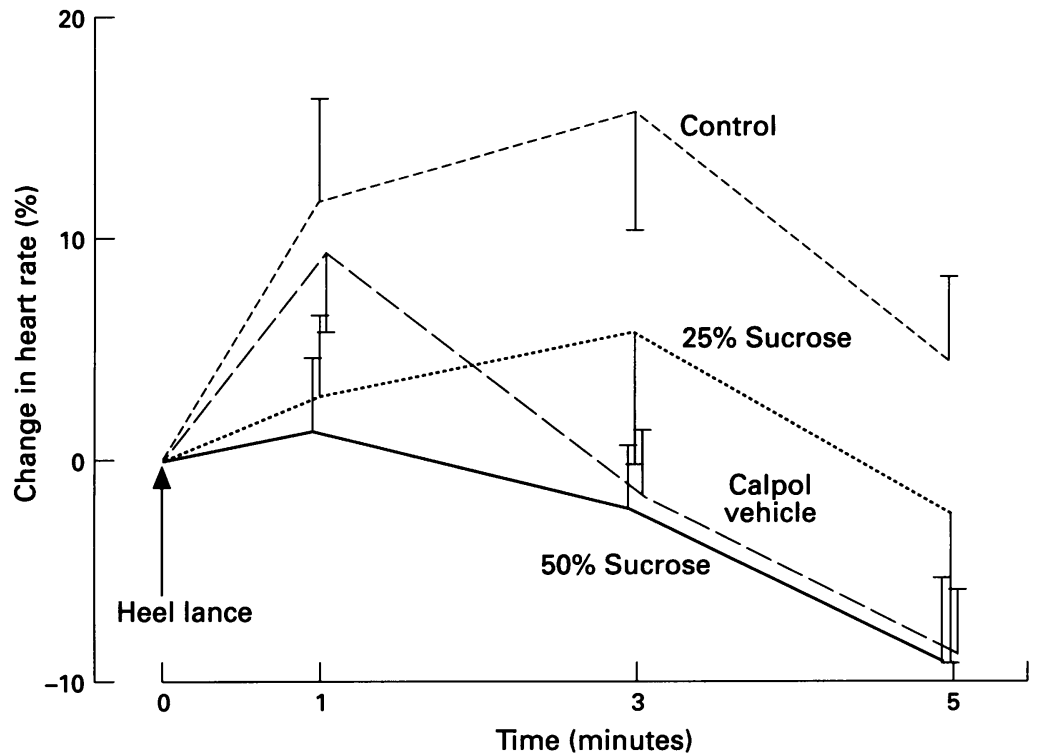

Figure 3 Percentage changes in heart rate following heel lance in the four groups of babies studied. non-nutritive sucking and the effect of sweet substances on behavioural response to the heel prick stimulus.

LR was supported by the Special Trustees of the Leeds Genera Infirmary. We are grateful to Burroughs Wellcome for supplying the Calpol solution.

1 Haouari N, Wood C, Griffiths G, Levene M. The analgesic effect of sucrose in full term infants. $B M \mathcal{F} 1995 ; 310$ 1498-500.

2 Taddio A, Goldbach M, Ipp M, Stevens B, Koren G. Effect of neonatal circumcision on pain responses during vaccination in boys. Lancet 1995; 345: 291-2.

3 Blass EM, Hoffmeyer LB. Sucrose as an analgesic for newborn infants. Pediatrics 1991; 87: 215-18.

4 Cheng LH, Robinson PP. The distribution of fungiform papillae and taste buds on the human tongue. Arch Oral papillae and taste buds

5 Ramenghi LA, Wood CM, Griffith GC, Levene MI Reduction of pain response in premature infants with intraoral sucrose. Arch Dis Child 1996; 74: F126-8.

6 Grunau RVE, Craig KD. Pain expression in neonates: facia action and cry. Pain 1987; 28: 395-410.

7 Grunau RVE, Johnston CC, Craig KD. Neonatal facial and cry responses to invasive and non-invasive procedures. Pain 1990; 42: 295-305.

8 Rushforth JA, Levene MI. Behavioural response to pain in healthy neonates. Arch Dis Child 1994; 70: F174-6.

9 Anand KJS, Phil D, Hickey PR. Pain and its effects in the human neonate and fetus. $N$ Engl $\mathcal{F}$ Med 1987; 317:

10 Blass EM, Fitzgerald E, Kehoe P. Interaction between sucrose, pain and isolation distress. Pharmacol Biochem Behav 1987; 26: 483-9.

11 Barr RG, Quek VSH, Cousineau D, Oberlander TF, Brian JA, Young SN. Effects of intra-oral sucrose on crying, mouthing and hand-mouth contact in newborn and sixweek-old infants. Dev Med Child Neurol 1994; 36: 608-18.

12 Lieblich I, Cohen E, Ganchrow JR, Blass E, Bergmann F. Morphine tolerance in genetically selected rats induced by chronically elevated saccharin intake. Science 1983; 97: 871-3.

13 Field T, Goldson E. Pacifying effects of nonnutritive sucking on term and preterm neonates during heelstick procedures. Pediatrics 1984; 74: 1012-15. 